\title{
LA ESTRUCTURA DE LA CLÁUSULA EN SEIS CUENTOS POPULARES DE MÉXICO
}

Continuando la serie de ensayos que he venido haciendo últimamente -la mayor parte de los cuales ha sido reunida en un volumen publicado hace poco ${ }^{1}$ - presento aquí los resultados obtenidos a través del análisis de seis fragmentos de otras tantas narraciones populares de Jalisco. Los textos elegidos para el estudio - todos ellos de similar extensión ${ }^{2}$ - pertenecen al libro de Stanley L. Robe, Mexican tales and legends from Los Altos ${ }^{3}$.

El procedimiento seguido en el análisis ha sido, en esencia, el mismo que utilicé al hacer los breves ensayos anteriores ${ }^{4}$ y que resumo aquí en pocas palabras. Las unidades lingüísticas a que presto atención son, de un lado, la cláusula y, de otro, la oración, el periodo, la frase y la prooración. Reservo el nombre de oración-de acuerdo con la secular tradición linguística española - al sintagma bimembre entre cuyos elementos se establece una relación predicativa. Corresponde a la fórmula de $\mathrm{Karl}$ Bühler $[\mathrm{S}-\mathrm{P}]^{5}$, interpretada no sólo como símbolo de la relación entre un sujeto gramatical y un predicado, sino también entre un tema (sea o no verdadero sujeto gramatical) y un comentario (sea de naturaleza verbal, nominal o adverbial). En consecuencia, son oraciones gramaticales indudables expresiones del tipo "Hubo toros", "Me fue muy bien en la prueba", "¿Qué estúpida respuesta!"o "Barriga llena, corazón contento" " 6 . Lla mo frase al enunciado, capaz de autono-

1 Cf. Análisis gramatical del discurso, UNAM, México, 1983.

De unas quinientas unidades léxicas cada uno; en total, alrededor de tres mil voces.

University of California Press, Berkeley-Los Angeles-Lond on, 1970. - Las muestras que he analizado corresponden a los cuentos siguientes: Muestra $1=$ Cuento $5(E I$ perro y' el colote), pp. 72-73; Muestra $2=$ Cuento 46 (Carmelita y Luisito), pp. 162-163; Muestra 3= Cuento 58 (Lanegra Angola), pp. 196-197; Muestra $4=$ Cuento 61 (El perro prielo), pp. 204-205; Muestra 5 = Cuento 73 (El caballo encantado), pp. 250-251; Muestra $6=$ Cuento 78 (Tata Juan), pp. 268-269.

$+\mathrm{Y}$ que ha quedado consignado en la primera parte del librito citado en la nota 1 , ạsí como en el artículo sobre "Unidades sintácticas. Recapitulación", $R F E, 61$ (1981), 29-63.

5 K. BüHler, Teoría del lenguaje. Rev. de Occidente, Madrid, 1950; cf. p. 414.

- En todas ellas se predica algo: la celebración, de la corrida de toros; mi éxito (el ir bien) en la prueba; la estupidez, de la respuesta, y la satisfacción o alegria, consecuencia de una buena comida. 
mía, que no está articulado en forma predicativa, sino que está constituido por un elemento nuclear -normalmente, un sustativo- solo o acompañado de elementos sintácticamente complementarios. Frases son elocuciones del tipo “¡Fuego!", "Buenas noches”, "Extraordinaria demanda de bienes raíces", "Alegría infantil en los rincones de las ciudades muertas", etc. Me sirvo del término prooración para designar al morfema o sintagma de estructura no oracional que implica - reproduce--, completándola de algún modo, una oración ya expresada. Así, "Esta noche" como respuesta a una oración interrogativa del tipo "¿Cuándo vas a hacerlo?", o "Con mucho cuidado" como comentario a una oración previa "Tenemos que meditarlo". La prooración -a diferencia de la frase-- carece de autonomía elocutiva. Distingo también entre prooración y oración elíptica, ya que esta última es una verdadera oración gramatical alguno de cuyos elementos constitutivos se o mite por estar claramente implícito, ya por la situación -contexto ambiental-, ya por haber sido expresado en un enunciado anterior - contex to linguístico. Entiendo por periodo la expresión constituida por dos -o, a veces, varias - oraciones (o frases) entre las que se establece una sola relación sintáctica, ya paratáctica, ya hipotáctica: "Se lo di para que no nos molestara más" o "Llegué, vi y vencí". Frente a todas estas unidades - de naturaleza esencialmente morfosintática-, la cláusula es la unidad mínima de comunicación, o sea, la expresión con autonomía elocutiva. Como fue ya definida, en 1558, por el licenciado Villalón, "cláusula es a las vezes vna oraçion sola y otras vezes es vn ayuntamiento de muchas oraçiones: las quales todas juntas espresan y manifiestan cumplidamente el conçibimiento del hombre en el propósito que tiene tomado para hablar" ${ }^{7}$. La cláusula no posee forma gramatical propia, dado que puede estar constituida por una sola palabra ("Adiós", "Perdón"), por un sintagma nominal o adverbial (de función prooracional: "QQuién lo hizo? - Mi hermano"), por una frase ("Tensa situación en el Medio Oriente"), por una oración ("Lo veré mañana en la oficina") o por uno o varios períodos ("Si viene, dile que no pude esperarlo más, porque tenía una cita en la oficina").

El análisis gramatical de los seis textos narrativos considerados proporciona el resultado que sintetizo en los cuadros siguientes:

\begin{tabular}{lrrrrrrr}
\multicolumn{7}{c}{ CuADRo I } \\
& \multicolumn{7}{c}{ Estructura general de las cláusulas } \\
& $\mathrm{M}-\mathrm{I}$ & $\mathrm{M}-2$ & $\mathrm{M}-3$ & $\mathrm{M}-4$ & $\mathrm{M}-5$ & $\mathrm{M}-6$ Promedio \\
Cláusulas & 62 & 52 & 55 & 43 & 26 & 43 & 46.8 \\
Oraciones & 108 & 121 & 116 & 106 & 101 & 107 & 109.8 \\
Oraciones por cláusula & 1.7 & 2.3 & 2.1 & 2.5 & 3.9 & 2.5 & 2.3 \\
Palabras por oración & 4.6 & 4.1 & 4.3 & 4.7 & 4.9 & 4.7 & 4.5 \\
Palabras por cláusula & 8.1 & 9.6 & 9.1 & 11.6 & 19.2 & 11.6 & 10.7
\end{tabular}

7 Gramática castellana, Amberes, 1558 (Ed. facsimilar de Constantino García, C.S.I.C., Madrid, 1971), p. 85. 


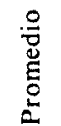

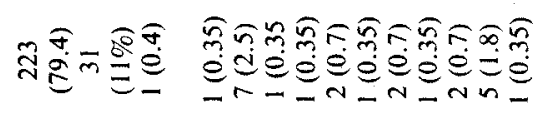

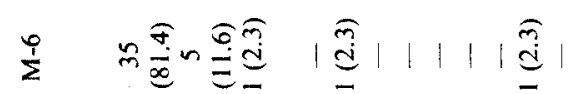

$\stackrel{n}{i} \quad \stackrel{0}{\underline{\theta}}$

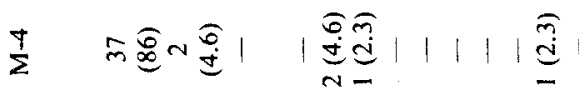

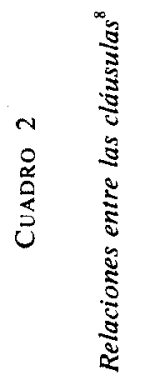

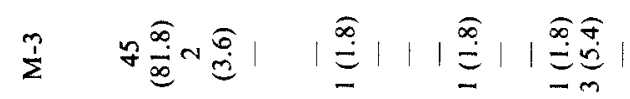

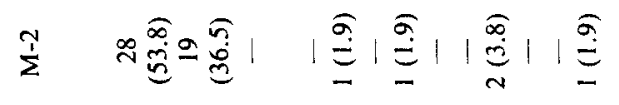

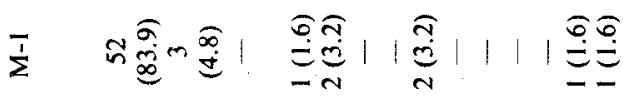

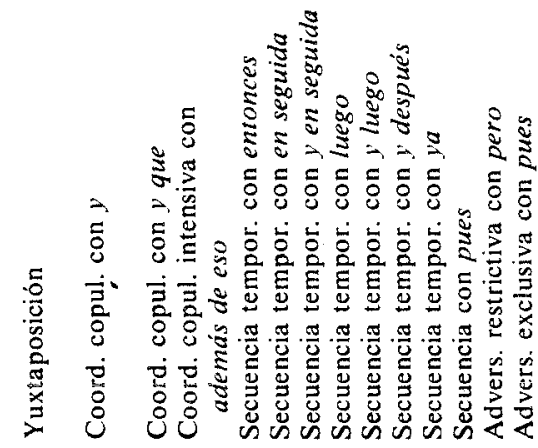




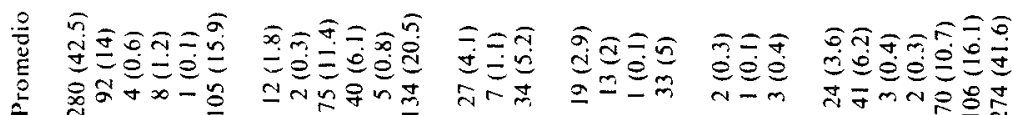

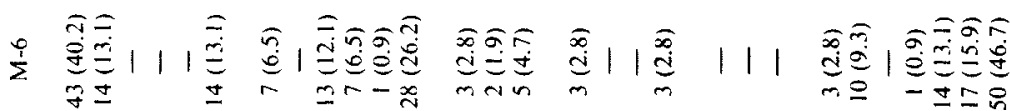

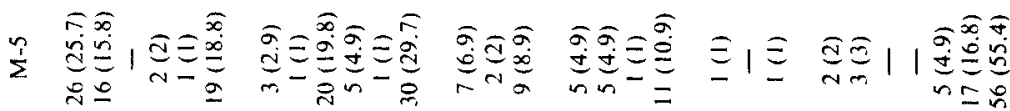

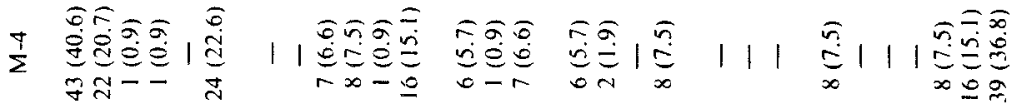

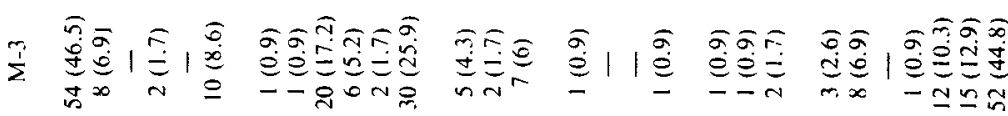

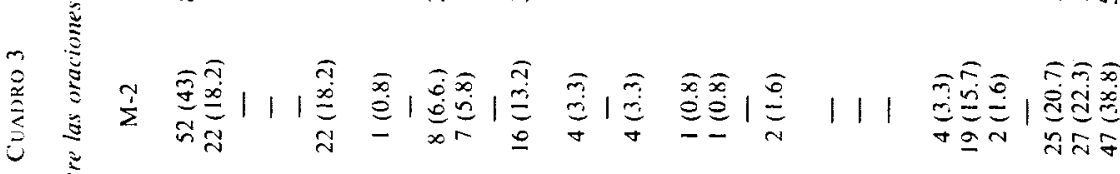

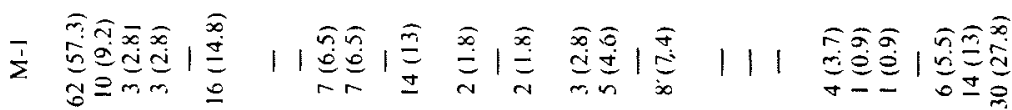

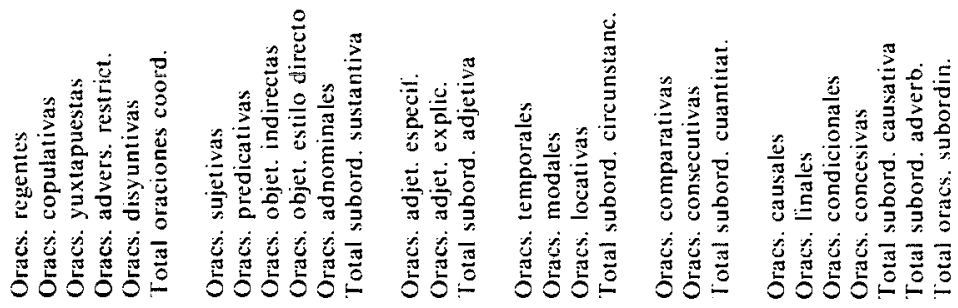


Sintesis

Oraciones regentes

Oraciones copulativas

Oraciones yuxtapuestas

Otras oraciones coordinadas

Oraciones subordin. sustantivas

Oraciones subordin. adjetivas

Oraciones subordin. adverbiales

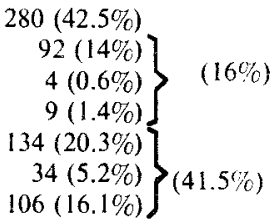

\section{Observaciones}

La estructura general de las cláusulas revela que la expresión narrativa popular posee fuerte homogeneidad en unos aspectos, pero notable diversidad en otros. En efecto, la oración gramatical de todas las muestras examinadas está constituida por un número muy semejante de unidades léxicas ${ }^{9}$ cuyo promedio general - de 4.5 unidades por oración-difiere sensiblemente del promedio representativo del habla culta hispanoamericana - que asciende a 7 unidades léxicas por oracióny más aún del promedio representativo del habla culta de la ciudad de México, donde sube hasta 7.8 unidades $^{10}$. La expresión popular se sirve, a juzgar por estos resultados, de los elementos léxicos indispensables, verdaderamente significativos, prescindiendo de los elementos complementarios (matizadores, calificativos). La extrema concisión léxica de las oraciones constitutivas de estas narraciones folklóricas supera, inclusive, el laconismo de la expresión característica del habla popular de la ciudad de México, donde el número de unidades léxicas integrantes, en promedio, de cada oración gramatical es 5.2 (cf. Análisis, p. 154). La ligera diferencia existente entre estas dos modalidades del habla popular (5.2 en la ciudad de México y 4.5 en los Altos de Jalisco) podría reducirse aún más si se considera que las muestras por mí analizadas en la capital del país reflejan la elocución espontánea, improvisada, de los hablantes urbanos populares, en tanto que las muestras jaliscienses corresponden a narraciones tradicionales, a textos ya dados. En consecuencia, el hablante urbano popular, por estar construyendo expresiones inéditas, improvisadas, recurre con relativa frecuencia al empleo de bordones, de muletillas (como bueno, este, verá usted, pues, etc.), que le proporcionan el tiempo necesario para ir organizando su pensamiento y conformando su expresión oral. En cambio, el narrador de los cuentos tradicionales da expresión oral a unos textos preexistentes, ya hechos y sabidos por él, de manera que no se ve precisado a servirse - al menos, no con tanta frecuencia como el hablante espontáneo, improvisador - de esos bordones innecesarios, los cuales elevan mecánicamente el número de

\footnotetext{
" Que oscila entre un mínimo de 4.1 (en la Muestra-2) y un máximo de 4.9 en la Muestra-5, la cual, como después veremos, resulta ser la más "literaria" o más "artística".

${ }^{10}$ Cf. mi Ariálisis (cit. en nota 1), p. 122.
} 
palabras integrantes de la oración gramatical característica del habla espontánea.

Volvamos a considerar nuestros textos folklóricos en sí mismos. Consecuencia de ese común laconismo en la constitución léxica de la oración gramatical es el hecho de que en las seis muestras estudiadas -todas ellas, repito, de similar extensión - se reúna un número semejante de oraciones gramaticales. La cifra más baja - de 101 oraciones - corresponde a la Muestra 5; la más alta - de 121 unidades oracionales- - a la Muestra 2. Ninguna de ellas se aleja excesivamente del promedio general, de prácticamente 110 oraciones por texto. Promedio al que se aproximan notoriamente las otras cuatro muestras analizadas.

Pero esta homogeneidad de los seis textos en lo que se refiere a la estructura de la oración gramatical se resquebraja intensamente en lo relativo a la estructura de la cláusula. Las diferencias existentes entre unos y otros textos son notorias; en especial, las existentes entre la muestra 1 y la muestra 5. Aquélla está constituida por un elevadísimo número de cláusulas: 62; ésta, en cambio, está integrada por sólo 26 cláusulas. Lo cual significa que en la primera se usa un $238 \%$ más de clá usulas que en la segunda. Y ambas se sitúan muy lejos del promedio general (de 47), al cual se aproximan, en cambio, las cuatro muestras restantes. Consecuencia inmediata de todo ello es que existan también grandes diferencias entre la estructura oracional de la cláusula típica de cada uno de los textos. En la muestra 1 - la más pobre o sencilla a este respecto - la cláusula está integrada por un promedio de sólo 1.7 oraciones gramaticales; en cambio, en la muestra 5 - la más compleja o rica - la cláusula está formada por un promedio de 3.9 unidades oracionales. Lo cual significa que ésta aventaja en un $230 \%$ a aquélla. Los otros cuatro textos se mantienen próximos al promedio general ( 2.3 oraciones por cláusula), el cual, por cierto, coincide casi exactamente con el promedio correspondiente al habla popular de la ciudad de México (2.1 oraciones por cláusula) ${ }^{11}$.

Todo esto, me parece, prueba algo que cabría esperar. Y es que todo narrador, por inculto que sea, tiene su propio estilo. El hablante popular, aun manteniéndose dentro de los ceñidos límites léxicos de la oración gramatical que parece serle familiar, construye su expresión con muy diverso aliento personal. Unos, como el narrador de la primera muestra, proceden mediante breves enunciados, bioracionales; otros, como el narrador de la quinta muestra, son capaces de organizar enunciados muy complejos, portadores de contenidos más amplios. Unos tienen mayor capacidad de abstracción que otros; unos son más capaces que otros de organizar mentalmente contenidos de conciencia complejos. La mayor capacidad de organización expresiva

1 Cf. Análisis, p. 108. O mi artículo sobre "Gramática y aprendizaje de la lengua materna", BAPuL, 6 (1978), 43-71. 
- o de estructuración de la cláusula como un todo que "manifiesta cumplidamente el concibimiento" del hablante, según el licenciado Villalón- de que da prueba el narrador de la muestra 5 queda confirmada por el hecho de que todas sus cláusulas se relacionen entre sí por simple yuxtaposición (cf. Cuadro 2), mientras que otros narradores tienen que servirse del recurso de enlazar unas cláusulas con otras por medio de nexos o palabras de enlace. El narrador del cuento de $E l$ caballo encantado no recurre siquiera al empleo de formas secuenciales (como entonces, luego, después, etc.) ni de coordinaciones copulativas interclausulares, a que recurren con frecuencia todos los demás narradores.

La excelencia de la calidad elocutiva propia del narrador 5 queda de manifiesto en su capacidad para organizar clá usulas amplias y complejas, constituidas por un elevado número de oraciones: "Pasó el tiempo y aquel niño creció, sabiend o todo lo que su padre adoptivo le enseñaba y, cuando ya el ermitaño no pudo enseñarle más, le dijo: - Quiero que me digas qué es lo que quieres, si seguir la ciencia o ir a dar una vuelta por el mundo" (p. 251). Frente a ello, la simple y recortada exposición peculiar del narrador de El perro y el coyote (muestra 1), basada en cláusulas muy sencillas, constituidas, generalmente, por una o dos oraciones gramaticales: "Había una vez una señora y un señor. Era un matrimonio muy feliz. No tenían hijos. Tenían un perro muy consentido. Le daban chocolate y pan y lo dejaban dormir en la alfombra. Una vez se enfermó la señora y se murió" (p. 72) ${ }^{12}$. El narrador de la muestra 5 revela capacidad en el uso del gerundio absoluto ("tan sólo encontró al caballo y no pensando qué hacer se arrimó él..."; "la mujer del mesonero, envidiosa, queriendo quedar bien con el rey... le dice") y de otras formas temporales, incluyendo el antepretérito ("una vez que hubo leido aquel ermitaño la carta, le dijo").

Entre esos dos extremos de máxima y mínima habilidad constructiva representados por los narradores 5 y 1 , los cuatro narradores restantes se mantienen en un discreto término medio ${ }^{13}$. La estructura sintáctica de sus enunciados, muy semejantes entre sí, se aproxima - de acuerdo con los índices numéricos obtenidos a través del análisis gramatical que sintetizo en el Cuadro 1-a los índices promedio. La forma de expresión de esos cuatro narradores podría representar el estilo sintáctico "neutro" o normal de la narración popular jalisciense;

\footnotetext{
12 Naturalmente que, en consecuencia, el número de palabras integrantes, en promedio, de cada cláusula sea muy diferente en uno y otro narrador: en el 5 , asciende a un asombroso 19.2, mientras que en el 1 apenas llega a 8.1 , es decir, menos de la mitad que en aquél.

${ }_{13}$ No resulta posible, lamentablemente, determinar si esa diversidad expresiva se debe -al menos en parte - a las caracteristicas personales de los distintos narradores. En el libro de Robe sólo se indica el lugar y la fecha de recopilación, asi como el nombre del narrador, pero nada se dice sobre su personalidad (edad, nivel cultural, idiosincrasia).
} 
existe entre ellos un elevado número de coincidencias o, al menos, de similitudes estructurales.

Notable es también la diversidad que se observa entre unos textos y otros en lo que respecta a la estructura oracional de las cláusulas (cf. Cuadro 3). En la muestra 5 -así como en la muestra 3-aparece una gran variedad de períodos; variedad que disminuye drásticamente en las demás muestras. El narrador de El caballo encantado utiliza, en el breve texto analizado, dieciséis clases diversas de períodos, y casi las mismas - quince- usa el narrador de La negra Angola (muestra 3), mientras que los narradores de los otros cuent os se sirven sólo de diez u once tipos de períodos. Pero las diferencias no son simplemente cuantitativas. En efecto, unos narradores se expresan, por lo general, a través de relaciones sintácticas sencillas, en las que predomina la simple coordinación de oraciones -como es el caso del narrador 1-, en tanto que otros se sirven de las más complejas y desusadas estructuras hipotácticas, como sucede especialmente en el caso del narrador 5, de nuevo el más capaz de todos. Así, mientras el primero recurre a la hipotaxis en sólo un $27.8 \%$ de las relaciones interoracionales, el último se sirve de ellas en un sorprendente $55.4 \%$, porcentaje que supera, inclusive, al correspondiente a la prosa literaria mexicana de nuestros días $(49.6 \%)^{14}$. En su breve narración hallamos -entre otros-períodos predicados, locativos y comparativos, que no son, en verdad, muy usuales en los restantes narradores.

Pero claro está que, dentro de esa evidente diversidad de estilos personales, la narrativa popular muestra indudable homogeneidad, una tónica común, fácilmente identificable. Veamos cuáles son, en conjunto, las peculiaridades sintácticas de esa modalidad del habla. En primer lugar, resulta ciertamente elevado - aunque no tanto como habría cabido imaginar - el número de oraciones que se relacionan mediante simple coordinación copulativa con la oración regente de la cláusula $(14 \%)^{15}$.

Muy alta es, también, la proporción de períodos objetivos (17.5\%), tanto en su forma indirecta $(11.4 \%)$, cuanto -aunque en menor medida - en el llamado estilo directo (6.1\%). La subordinación sustantiva, en general, resulta ser abundante en la narrativa popular $(20.5 \%)$.

14 Cf. Análisis, p. 102, o mi articulo "La estructura del discurso en cinco escritores mexicanos", en Festschrift for Jacob Ornstein: Studies in general linguistics and sociolinguistics, ed. by E.L. Blansitt and R.V. Teschner, Rowley, Mass., 1980, p. 169. Sólo un escritor tan elaborado como Alfonso Reyes alcanza un promedio de oraciones subordinadas $(70.3 \%)$ muy superior al del narrador popular jalisciense.

'Digo que habría cabido imaginar un índice mayor por cuanto que el promedio de períodos copulativos en la lengua literaria mexicana de nuestro tiempo llega al $15.5 \%$. Y la simple coordinación copulativa de oraciones - en un esquema o molde del tipo "llegó a su casa .l' cenó un poco y' se fue a dormir"- suele considerarse representativa del habla popular... o infantil. 
Pero no sucede lo mismo en el caso de los períodos adjetivos, relativamente escasos en esta modalidad del habla popular $(5.2 \%)$, sobre todo en su forma explicativa ( $1.1 \%)$. Pienso que la razón de esa notable diferencia en el uso de períodos sustantivos y adjetivos puede estar en el carácter mismo de la expresión popular, afecta a considerar sólo los elementos esenciales, sustantivos, de la comunicación, en detrimento de los complementarios u ornamentales. De ahí que las oraciones objetivas, elementos muchas veces nucleares del período(de las "oraciones compuestas" ${ }^{16}$ ), surjan con alta frecuencia en los comunicados populares, en tanto que las oraciones adjetivas, verdadera y simplemente complementarias, hacen acto de presencia con menor regularidad; en especial, las explicativas, ya que las especificativas sí cumplen funciones más importantes, en cuanto delimitativas.

Las complementaciones de carácter adverbial - tal vez por la misma razón- tampoco parecen gozar del favor de los hablantes populares. Las determinaciones de lugar, tiempo y modo apenas alcanzan, en su conjunto, un $5 \%$ de vitalidad. Hay, como después veremos, otras razones, internas - propias del sistema lingüístico español-, que explican ese bajo índice de aparición de los períodos subordinados circunstanciales.

Pero, en cambio, otra clase de hipotaxis adverbial goza indudablemente de las preferencias populares: la causativa. Tanto en su forma eficiente como en la final. En los cuentos analizados, esas dos relaciones causativas están ampliamente representadas, hasta alcanzar un total de $9.8 \%$ de incidencia. De la subordinación causal propiamente dicha $(3.6 \%)$ hay testimonios en todos los textos. Más frecuente es aún la subordinación final $(6.2 \%)$, aunque en una de las muestras -la $n^{\circ}$ 4 - no se documenta ningún ejemplo. Parece indudable que al ser humano le preocupa hondamente el porqué y el para qué de las cosas. Los resultados del análisis de los cuentos populares de Los Altos coinciden, con gran precisión, con los obtenidos en otros ensayos de análisis de la lengua hablada en la actualidad. En efecto, en la norma linguística culta de la ciudad de México, los índices de aparición de períodos causativos están muy próximos a los descubiertos en la narrativa jalisciense: ascendían al $7.5 \%{ }^{17}$. Mayor proximidad se advierte aún en el caso de la lengua popular de la capital mexicana: $10.4 \%$ de oraciones causativas. En cambio, la lengua literaria of rece menos testimonios de esas formas de relación: apenas un $4.2 \%$, menos de la mitad que en la lengua hablada.

Formas mucho menos frecuentes de relación oracional son la distributiva y la ilativa - ningún testimonio en nuestros textos-, así como $91-104$

16 Cf. mi artículo sobre "El concepto de oración compuesta", en BdFS, 30 (1979),

${ }^{17}$ De él, $4 \%$ correspondía a los períodos causales y $3.5 \%$ a los finales. Cf. Análisis, p. 109, o ta mbién mi artículo "La estructura de la cláusula en el habla y en la literatura", ALM, 17 (1979), p. 112. 
la locativa, la disyuntiva, la consecutiva (un solo testimonio en cada caso) y la concesiva (dos casos). Pero ello no es, de ningún modo, peculiaridad de los textos narrativos considerados, sino característica de la propia sintaxis española. En todos los textos por mí estudiados anteriormente, estas clases de períodos suelen ser muy escasos ${ }^{18}$. En cambio, otros períodos parecen ser imprescindibles para la expresión española. En todos nuestros cuentos han aparecido, con mayor o menor profusión -además de los causales y objetivos-, períodos copulativos (14\%), adjetivos especificativos (4.1\%) y temporales $(2.9 \%)$. Lo mismo sucedía en todos los demás textos analizados por mí en ensayos anteriores.

En comparación con todos esos textos, los cuentos populares de Los Altos presentan algunas otras características dignas de ser consignadas. La sencillez léxica de la oración gramatical alcanza en estos relatos populares su máxima expresión. Inclusive la apretada estructura léxica de la oración peculiar de Quevedo queda superada por estas narraciones jaliscienses. En el escritor conceptista, el número de palabras, en promedio, por cada oración gramatical, se reducía a 5.2, exactamente lo mismo que en el habla popular de la ciudad de México; en los cuentos ahora estudiados, se reduce aún más: 4.5 únicamente.

También es extrema la simplicidad léxica de la cláusula característica de estas narraciones populares; se constituye, en promedio, con sólo 10.7 unidades léxicas ${ }^{19}$. En cambio, la cláusula quevedesca - amplia, complejísima - está integrada por más de 25 palabras. Sólo Baltasar Gracián, de entre los autores por mí estudiados, construye cláusulas casi tan lacónicas, tan apretadas, como las de los narradores jaliscienses ${ }^{20}$. Lo cual depende, obviamente, de la sencillez oracional de la cláusula peculiar tanto del escritor aragonés ( 2.9 oraciones por cláusula) cuanto de los narradores de Los Altos $(2.3)^{21}$.

Decía antes que determinadas oraciones complementarias - adjetivas, explicativas, circunstanciales en sus tres modalidades, etc. - son relativamente escasas, no sólo en los textos folklóricos de Jalisco, sino también en la sintaxis española general. Ello puede deberse a que se hallan en competencia con complementos no oracionales de igual

\footnotetext{
18 Con algunas aisladas excepciones. Los períodos distributivos y los consecutivos a lcanzan índices relativamente altos en La cárcel de amor de Diego de San Pedro(5\% y $5.75 \%$ respectivamente); y los concesivos, en las Cartas de Diego de Ordaz (3.1\%). Cf. Análisis, pp. 136, 137 y 151.

${ }^{19}$ En perfecta coincidencia con la cláusula propia del habla popular espontánea de la ciudad de México (10.8). Cf. Análisis, p. 154.

20) En sus ensayos, el promedio de voces constitutivas de cláusula se reduce a 13.5. (Cf. mi estudio sobre "La estructura del discurso en el Oráculo manual", que se publicará en el Homenaje a Tomás Buesa Oliver).

"La cláusula de la prosa de Quevedo, en cambio, está integrada por un promedio altísimo- de 4.9 oraciones gramaticales, que es el más elevado de los registrados por mí en todos los análisis hechos hasta ahora.
} 
función. En el Cuadro 4 recojo los resultados del análisis hecho a este respecto.

Complementos adjetivos

Complementos predicativos

Complementos objetivos

Complementos prepositivos

Complementos adnominales

$\begin{array}{lllllll}\text { M-1 } & \text { M-2 } & \text { M-3 } & \text { M-4 } & \text { M-5 } & \text { M-6 } & \text { Total Total }\end{array}$

Complementos temporales

Complementos locativos

Complementos modales

Complementos cuantitativos

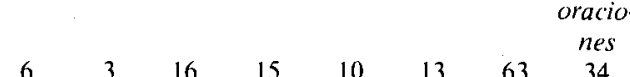

Complementos causales

Complementos finales

Complementos condicionales

Complementos concesivos

Este cuadro permite advertir, a simple vista, las circunstancias siguientes:

A) Hay ciertas clases de complementaciones que, en español, suelen expresarse por medio de sintagmas no oracionales, y no por verdaderas oraciones gramaticales.

B) Otros tipos de complementaciones, por el contrario, se suelen expresar mediante estructuras oracionales, y no por medio de complementos no oracionales.

C) En algunos casos, existe un mejor equilibrio entre ambas formas de complementación.

En efecto, las narraciones folklóricas consideradas muestran, en primer lugar, que los predicados nominales - normalmente adjetivos morfológicos- son muchísimo más usuales $(57=96.6 \%)$ que las oraciones predicativas $(2=3.4 \%)$. Asimismo, los complementos prepositivos (del tipo "desconfío de su lealtad") son los únicos que, con tal función, han aparecido en nuestros textos.

De semejante manera, las determinaciones de lugar corren a cargo, casi exclusivamente, de complementos adverbiales locativos $(80=$ $98.7 \%$ ), y muy rara vez son desempeñadas por oraciones subordinadas locativas $(1=1.3 \%)$.

También las determinaciones cuantitativas suelen ser expresadas, de manera abrumadora, por sintagmas complementarios $(84=96.4 \%)$, no por oraciones gramaticales $(3=3.6 \%)$.

En cambio, las explicaciones causales suelen tener expresión oracio- 
nal $(24=80 \%)$, con muy a mplia ventaja sobre las formas complementarias no oracionales $(6=20 \%)$. Esta peculiaridad se advierte, aún más tajantemente, en el caso de la expresión de la fïnalidad, que en nuestros textos queda siempre a cargo de estructuras oracionales $(41=100 \%)$. Asimismo, la expresión de las condiciones y de las relaciones concesivas corresponde siempre - en los escasos ejemplos documentados - a oraciones gramaticales ( 3 y 2 testimonios, respectivamente).

Armonioso equilibrio se advierte, en cambio, en el caso de la complementación objetiva, la cual está a cargo de estructuras oracionales en 115 ocasiones $(43.4 \%)$ y de complementos nominales en 150 casos $(56.6 \%)$.

También en las determinaciones de carácter adjetivo existe cierto equilibrio: el uso de las expresiones oracionales $(34=35 \%)$ no está demasiado lejos del empleo de adjetivos morfológicos $(63=65 \%)$. Pero no sucede lo mismo en el caso de las complementaciones adno minales, a cargo de estructuras predicativas sólo en 5 ocasiones $(=11.9 \%)$ y de sintagmas sustantivos no oracionales en 37 casos $(=88.1 \%)$.

No es tampoco excesivamente desequilibrada la proporción existente entre complementaciones modales de carácter oracional $(13=$ $27.7 \%$ ) y complementos adverbiales de modo $(34=72.3 \%)$.

Mucha mayor desproporción existe ya entre las determinaciones temporales expresadas por verdaderas oraciones gramaticales ( $19=$ $16.2 \%)$ o por complementos no oracionales $(98=83.8 \%)$.

Por otra parte, cada una de estas diversas clases de complementaciones presenta muy diferente vitalidad en los textos analizados, en coincidencia con lo que también sucede en la lengua española general.

Las complementaciones de carácter sustantivo son las más frecuentes, en especial los complementos objetivos $(150+115=265)$. Pero cierto es que tales determinaciones no son, propiamente, elementos lingüísticos verdaderamente complementarios, sino parte sustancial, constitutiva, del sintagma predicativo y, por ende, de la misma oración gramatical.

Muy frecuentes son también, relativamente, las complementaciones adjetivas, en especial las especificativas. En nuestros cuentos alcanzan un total, nada desdeñable, de 139 testimonios, 63 de los cuales $(=45.3 \%)$ corresponde a adjetivos morfológicos y $34(=24.5 \%)$ a oraciones subordinadas, en tanto que el resto $(42=30.2)$ queda a cargo de complementos adnominales (37) y, sólo ocasionalmente, de oraciones de igual función (5).

Frecuentes son asimismo las determinaciones de carácter circunstancial (245 en total), sobre todo las temporales (¿tal vez por la importancia que el tiempo tiene en la vida - breve - del hombre, en especial en la cultura cristiana?), las cuales ascienden en nuestros textos a la nada desdeñable cifra de 117 .

No son tampoco insignificantes las complementaciones causativas, según queda consignado en líneas anteriores. 
En cuanto a la naturaleza de cada uno de estos tipos de complementos no oracionales, cabe advertir que, en las narraciones folklóricas de Los Altos, los complementos cuantitativos son poco variados; Por lo general, se trata de adverbios simples, como muy (38 casos), tan (19), más (12), mucho (5), tanto (4) y unos pocos más aislados.

En cambio, los complementos modales son enormemente variados, a tal grado que se resisten a todo intento de clasificación coherente: $a$ puntapiés, en pañales, con un capricho, de repente, así, etc.

También los complementos locativos y temporales presentan gran variedad, pero, dentro de ella, una buena parte podría ordenarse en torno a ciertos lexemas relativamente reiterados. Así sucede en el caso de las determinaciones temporales ${ }^{22}$ : un día (3), el dia (1), otro dia (1), todos los días (2), a los ocho dias (= 'una semana': 1); en la noche (4), de noche (1), la noche (1), en toda la noche (1), a la siguiente noche (1), a medianoche (1); mañana (3) todas las mañanas (1), a la mañana siguiente (1); en la tarde (1), ayer (1), (muy) temprano (7); ahora (5), ora (3), oritita (3); (al) rato (2), a(l) poco rato (2), un ratito (1); (durante) un año (2), varios meses (1); en seguida (2), de momento (= 'en seguida': 1), pronto (1); ya (14), entonces ${ }^{23}(10)$, luego ${ }^{24}(14)$, después (1), entre tanto (1), una vez (5), todavia (1) y algún otro.

Más heterogéneos son los complementos de carácter locativo que aparecen en los cuentos jaliscienses. Enumero una buena parte de ellos ${ }^{25}$ : aquí (6), allí (4), allá (6), ahi, por ahí, por allá; (a) dentro (2), cerca, muy lejos, a lo lejos (2), atrás, adelante, junto, allá arriba, (de) en frente (2), a su casa (2), a la casita, al cerro (2), al pie de un cerro, en el bosque, entre el monte, a orilla del rio, hasta el arroyo, al agua, en el agua, a una huerta, a un árbol, en el desierto, al corral, al muladar, en el palacio, a su trono, al estrado, por el mundo, etc. Como puede advertirse, muchos de ellos hacen referencia a diversos elementos de la naturaleza (cerro, monte, bosque, rio, arroyo, huerta), como cabría esperarse, dado el carácter mismo de los cuentos, así como del ambiente en que se han perpetuado y, también, en que se originó, hace muchos años - a veces, siglos - la mayor parte de los cuentos tradicionales.

Una observación final: Es muy reducido el número de unidades enunciativas no oracionales que aparecen en estas narraciones. En total, sólo ocho prooraciones y siete frases. De las primeras, buena parte corresponde a adverbios negativos constitutivos de respuesta (“- - Ya no te quieren? - ¡No!”. “... algún piojito debe haber criado.

$\because$ En la enumeración que sigue, la cil ra colocada entre paréntesis a continuación de cada forma indica el número de sus apariciones en el conjunto de la muestra.

2.3 En uso estrictamente temporal, sin contar los también abundantes casos de entonces con valor puramente ilativo.

' 2+ En no pocos casos, con sentido de inmediación en la sucesión de las acciones, según es común en el habla de todo México.

Si no indico, entre paréntesis, el número de sus apariciones, debe entenderse que se documentaron una sola vez. 
- No, le dijo"). Sintagmas causales cumplen la función prooracional en tres ocasiones dentro de un mismo cuento (Muestra-3: "¿Por qué estás tan prieta?" - - Ay, hijo! Pues por el sol. - ¿Por qué estás tan china? — Ay, mi cielo! Por el sereno. - ¿Por qué estás tan fea? -iAy, chiquito! Por el aire"). De las siete frases, cuatro corresponden a la fórmula de saludo Buenos días. En su totalidad, estas frases y prooraciones pertenecen a pasajes dialogísticos, no a los narrativos. Todo ello comprueba, una vez más, que la forma de expresión natural, absolutamente mayoritaria, en nuestra lengua es la oración gramatical ${ }^{26}$.

De todas las modalidades de la lengua española que he tenido oportunidad de analizar, la representada por estas narraciones folklóricas resulta ser la más concisa y densa, la más descarnada. Los enunciados atienden, casi exclusivamente, a los elementos fundamentales, imprescindibles para la comunicación de los contenidos. De ahí que la oración gramatical sea, en esos textos, sumamente concisa, apretada ${ }^{27}$ y - en consecuencia - sea igualmente austera la constitución léxica de la cláusula ${ }^{28}$. Expresión, pues, recortada, sustancial, que gana en intensidad conceptual lo que pierde en elaboración artística.

JUAN M. LOPE BLANCH

Universidad Nacional Autónoma de México.

El Colegio de México.

\footnotetext{
26 Observaciones éstas fácilmente previsibles, que ya había hecho casi intuitivamente: "(La oración es) la estruct ura gramatical básica de toda comunicación linguística. En cambio, frases y prooraciones son formas expresivas peculiares de ciertos tipos o géneros comunicativos. En líneas generales, la frase resulta ser estructura característica de la expresión poética, en tanto que las prooraciones son formas casi exclusivas del diálogo" (cf. "Notas sobre las unidades sintácticas del discurso", $A L M$, 20 (1982), p. 336; o Análisis, p. 63).

${ }^{7}$ Recuérdense algunos datos estadísticos. Número de unidades léxicas constitutivas, en promedio, de oración gramatical: Cuentos jaliscienses $=4.5$; Habla urbana popular $=5.2 ;$ Habla culta $=7$; Lengua literaria $=7$.

¿- Número de unidades léxicas, en promedio, por cláusula: Cuentos tradicionales = 10.7; Habla popular $=10.8$; Habla culta $=25.7$ Lengua literaria $=21.8$.
} 